\title{
The effects of rehabilitation education for village health volunteers on walking speed and upper extremity function in stroke survivors in Thailand
}

\author{
Pisak Chinchai, BSc OT (Chiang Mai University, Thailand), MEd (Health Promotion), MA (OT) (University \\ of Southern California), PhD (OT) (Curtin University, Australia) \\ Assistant Professor, Department of Occupational Therapy, Faculty of Associated Medical Sciences, Chiang Mai University, Thailand
}

Peanchai Khamwong, BSc PT (Khonkeen University, Thailand), MS (Physiology of Exercise) (Mahidol

University Thailand), PhD (Biomedical Science) (Chiang Mai University, Thailand)

Assistant Professor, Department of Physical Therapy, Faculty of Associated Medical Sciences, Chiang Mai University, Thailand

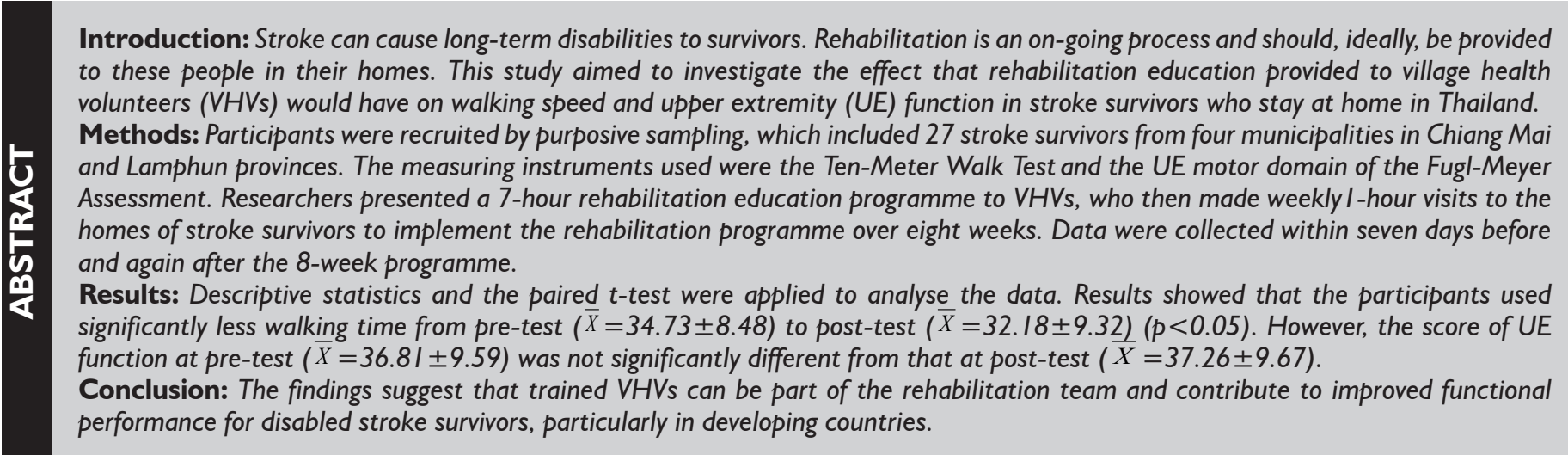

Key words: Hand function, gait speed, Home visit, motor function after stroke, community rehabilitation, home-based rehabilitation

\section{INTRODUCTION}

Stroke is one of the most common conditions found in Thailand and is the fourth leading cause of death after heart disease, traffic accidents and cancer ${ }^{1,2}$. Approximately $90 \%$ of stroke survivors have residual disabilities, such as muscle weakness on one side of the body and sensory disturbances that lead to limited performance in walking ${ }^{3-5}$ and impaired upper extremity (UE) function ${ }^{4,7}$. This results in problems with activities of daily living $(A D L)^{8-10}$ and community participation"'.

Currently, healthcare and rehabilitation systems in Thailand (a developing country) emphasise treatment in institutional settings, while less attention is payed to the lives of disabled people at home and in the community. Individuals with disabilities, including stroke survivors, suffer as a direct consequence of the lack of care or help from any health service organisations. Caring for older adults with chronic diseases can be a burden to family caregivers causing emotional distress, social isolation and occupational imbalance ${ }^{12}$. Therefore, it is crucial that health professionals find strategies to care for persons with chronic diseases at home and also to relieve the day-to-day burdens of family caregivers.

Rehabilitation professionals in Thailand (mainly occupational therapists and physiotherapists) who work in hospitals or institutional settings, are overwhelmed by heavy workloads in their routine tasks and are therefore unable to allocate sufficient time to community visits. In this country, community dwellers, who are known as village health volunteers (VHVs), have been assigned by local health organisations to participate in the healthcare system. The role of the VHVs is to assist local health professionals in provid- ing care for the people in their own village. VHVs are also active in taking care of peoples' general health in their own community in terms of health promotion and the prevention of disease ${ }^{13,14}$ However, none of them take part in rehabilitating disabled persons. This study therefore aimed to study the impact of rehabilitation education on the VHVs who visit the homes of disabled people. To the authors' knowledge, this is the first study in Thailand to recruit VHVs as members of the rehabilitation team.

\section{LITERATURE REVIEW}

Stroke can have devastating effects on the physical function of survivors. The most significant physical impact on stroke survivors is long-term disability ${ }^{15}$. Paresis of muscles in both the lower extremity (LE) and UE can be an obstacle to independent living. Walking ability ${ }^{4,15}$ and UE function ${ }^{16}$ are thus crucial for enhancing functional abilities in the everyday life of people with disabilities due to stroke.

\section{Walking speed}

Walking (locomotion) is a significant part of functional recovery following stroke and this function can be hampered by various factors, including the severity of muscle weakness, inadequate body endurance, poor standing balance and lack of training. Kosak and Reding ${ }^{17}$ mentioned that $75 \%$ of stroke survivors have hemiparesis, and initially, $50 \%$ are unable to walk even with assistance. Jorgenson et $\mathrm{al}^{18}$, also noted that 3 months after a stroke, $25 \%$ of such individuals were still unable to walk and became wheelchair-dependent. Gait can be a major determinant of independent living in people with disabilities ${ }^{15}$. The improvement of this function is therefore, 
Table I: Motor recovery after stroke ${ }^{26}$

\begin{tabular}{|c|c|c|c|}
\hline Stage & Leg & Arm & Hand \\
\hline 1 & Flaccidity & Flaccidity & No hand function \\
\hline 2 & $\begin{array}{l}\text { Spasticity develops, minimal voluntary } \\
\text { movements }\end{array}$ & $\begin{array}{l}\text { Beginning development of spasticity; limb } \\
\text { synergies or some of their components } \\
\text { begin to appear as associated reactions }\end{array}$ & $\begin{array}{l}\text { Gross grasp beginning, minimal finger } \\
\text { flexion possible }\end{array}$ \\
\hline 3 & $\begin{array}{l}\text { Spasticity peaks, flexion \& extension } \\
\text { synergy present, hip-knee-ankle flexion in } \\
\text { sitting \& standing }\end{array}$ & $\begin{array}{l}\text { Spasticity increasing; synergy patterns } \\
\text { or some of their components can be } \\
\text { performed voluntarily }\end{array}$ & $\begin{array}{l}\text { Gross grasp, hook grasp possible, no } \\
\text { release }\end{array}$ \\
\hline 4 & $\begin{array}{l}\text { Knee flexion past } 90 \text { degrees in sitting, } \\
\text { with the foot sliding backward on the floor; } \\
\text { dorsiflexion with the heel on the floor \& the } \\
\text { knee flexed to } 90 \text { degrees }\end{array}$ & $\begin{array}{l}\text { Spasticity declining; movement } \\
\text { combinations deviating from synergies are } \\
\text { now possible }\end{array}$ & $\begin{array}{l}\text { Gross grasp present, lateral prehension } \\
\text { developing, small amount of finger } \\
\text { extension \& some thumb movement } \\
\text { possible }\end{array}$ \\
\hline 5 & $\begin{array}{l}\text { Knee flexion with the hip extended in } \\
\text { standing, ankle dorsiflexion with the hip \& } \\
\text { knee extended }\end{array}$ & $\begin{array}{l}\text { Synergies no longer dominant, more } \\
\text { movement combinations deviating from } \\
\text { synergies performed with greater ease }\end{array}$ & $\begin{array}{l}\text { Palmar prehension, spherical \& cylindrical } \\
\text { grasp \& release possible }\end{array}$ \\
\hline 6 & $\begin{array}{l}\text { Hip abduction in sitting or standing, } \\
\text { reciprocal internal \& external rotation of } \\
\text { the hip combined with inversion \& eversion } \\
\text { of the ankle in sitting }\end{array}$ & $\begin{array}{l}\text { Spasticity absent except when performing } \\
\text { rapid movement, isolated joint } \\
\text { movements performed with ease }\end{array}$ & $\begin{array}{l}\text { All types of prehension, individual finger } \\
\text { motion, full range of voluntary extension } \\
\text { possible }\end{array}$ \\
\hline
\end{tabular}

often the main priority for stroke survivors ${ }^{19}$. Walking speed (or gait velocity) is a reliable measurement for assessing improvement in walking performance. The gait cycle in humans can be divided into two phases: the stance phase, in which the leg is in contact with the floor, and the swing phase, in which the leg is off the floor. The stance phase consists of approximately $60 \%$ of the gait cycle and the swing phase about $40 \%{ }^{20}$. The phases of stance and swing are further divided into sub-stages. The stance phase consists of heel strike, foot flat, mid-stance, heel off and toe off, while the swing phase comprises acceleration of step, mid-swing and step deceleration. Heel strike is the beginning of the stance phase, which occurs when the heel makes contact with the floor. Foot flat is the stage when the sole of the foot is fully in contact the ground. Mid-stance is the point at which the body passes directly over the reference extremity, followed by heel off and toe off, where the heel and the toe of the reference extremity leave the floor respectively. Acceleration of the swing phase starts from the moment the toe of the reference extremity leaves the ground to the point when the reference extremity is directly under the body. Mid-swing is the period when the reference extremity passes directly below the body. Deceleration of the step is the phase when the reference extremity decelerates in preparation for the heel strike ${ }^{20}$. Understanding the gait cycle is crucial for therapists and caregivers to enhance walking skills in people with disabilities under their care.

\section{Upper extremity function}

UE dysfunction is one of the most common and challenging sequelae of a stroke. Inability to use the UE properly is common after stroke, with $88 \%$ of clients who suffered a stroke having some degree of UE dysfunction ${ }^{21}$. The recovery of motor function plateaus at about one year following a stroke ${ }^{22}$, especially in the arms and hands ${ }^{23}$. The ability to integrate the affected UE into purposeful tasks may be limited by several factors including I) pain; 2) contracture and deformity; 3) loss of motor control; 4) weakness; 5) super-imposed orthopaedic limitations; 6) loss of postural control; 7) learned non-use; 8) loss of biomechanical alignment, and 9) inefficient and ineffective movement patterns ${ }^{24}$. The current model of motor behaviour development supports the use of function-based tasks or task-specific training ${ }^{24}$. The treatment of the hand and UE function in persons with disabilities is more relevant to occupational therapy than others in the rehabilitation team because this profession focuses on task-specific intervention.

There are a variety of motor control models that have been proposed for occupational therapy professionals for use in their clinical intervention. However, the complex problems that interfere with UE function may require integrated treatment techniques that use functional tasks as the intervention mechanism. Functional tasks in therapy include occupations that require UE weight-bearing for postural support, reaching, grasping, holding, lifting, carrying and manipulating various kinds of objects ${ }^{24}$. Therefore, the UE evaluation and training should focus on the client's ability to integrate the UE into the performance of functional tasks $\mathrm{s}^{21,24}$. There are many evaluation tools that are regularly used for the measurement of UE function. One of the standard instruments that is popular among therapists is The Fugl-Meyer Assessment ${ }^{25}$.

\section{Motor recovery after stroke}

Stroke can have distinct patterns of recovery and detailed knowledge of the course of recovery can benefit the design of an appropriate rehabilitation programme. Brunnstrom ${ }^{26}$ identified six stages of motor recovery after stroke in the leg, arm and hand, as illustrated in Table I. Differences of recovery levels and rates can affect the functional performance of individuals following stroke.

However, vigorous and repetitive training can help regain motor skills at any time after a stroke ${ }^{27}$. Therefore, rehabilitation of both upper and lower extremities following a stroke is crucial for enhancing functional skills in disabled patients, even after hospital care $^{28,29}$. Dobkin ${ }^{30}$ noted that improved walking ability and arm movement would lessen disability and limitations in the daily lives of persons with hemiplegia.

\section{The Role of VHVs in Thailand}

VHVs are considered a community health work-force in Thailand. Their duties have long been recognised as the driving force of community-based public health. In 2010 there were more than 800,000 active volunteers, covering over 12 million households throughout every province ${ }^{31}$. To ensure VHVs understand the needs of people in the community, community members are informally encouraged by village leaders and primary health care station staff to apply for VHV positions. After acceptance through a formal application process, each volunteer receives seven days of training in primary health care and 15 days of specialised on-the-job training in health promotion, disease prevention, and health education. Following this training, VHVs are assigned to assist 7-1 5 households in their communities and work under the supervision of public health officials ${ }^{32}$. Their responsibilities include (but are not limited to) taking care of the general health of people in their own communities and also the prevention of communicable diseases in the villages. Currently, public health problems such as malnutrition and infectious disease are declining in Thailand ${ }^{13,33}$ and the $\mathrm{VHVs}$ are more 
generally tasked with chronic disease prevention and management. However, the role of VHVs has to date, not included community rehabilitation

In Thailand, a large number of stroke survivors are left unattended at home, some of whom do not try to help themselves, but instead wait for spontaneous recovery. Many survivors are confined to bed with no access to any rehabilitation programme outreach. It is important that the rehabilitation team provide a training programme for stroke survivors to ensure continuity of care from the hospital to the home and community. A number of studies have revealed the benefits of rehabilitation education to family caregivers regarding the functional performance of disabled persons under their care. Thorsén et $\mathrm{al}^{34}$ studied the effects of early discharge from hospital and continued rehabilitation at home after a stroke. A five-year follow up study was performed in southwest Stockholm with 54 participants (30 and 24 in the intervention and control group, respectively). The results demonstrated that stroke survivors in the intervention group were more independent in activities of daily living and more actively participated in household activities than those in the control group. Chinchai and Bunyamark ${ }^{35}$ studied the effects of caregiver education in stroke rehabilitation on community participation of stroke survivors in Thailand. Sixty stroke survivors who participated in their study were divided into two groups of 30 each, with one being an experimental group that received rehabilitation education from healthcare providers, and the other the control group. Results demonstrated that the participants in the experimental group improved their ability in community participation significantly more than those in the control group.

\section{METHODS}

\section{Study aim}

To investigate the effects of rehabilitation education provided to $\mathrm{VHVs}$ on the walking speed and UE function of stroke survivors staying at home.

\section{Study design and Ethics}

This study was a single group, pre-test- post-test research design. The research project was approved by the Ethics Committee of the Faculty of Associated Medical Sciences, Chiang Mai University, in Thailand (Ethics number: 218/2557).

\section{Study participants}

The research participants were stroke survivors selected by means of purposive sampling from four out of the 10 major municipalities approached. Researchers in Thailand have to obtain permission from the municipality before beginning any research projects in that area. Invitations were issued to 10 municipalities located less than I 00 kilometres from Chiang Mai University. The four municipalities that collaborated with this study were; I) Nongkwauy municipality, Hang Dong district, Chiang Mai province; 2) Nongkaew municipality, Hang Dong district, Chiang Mai province; 3) Maerang municipality, Pasang district, Lamphun province; and 4) Makok municipality, Pasang district, Lamphun province. After all four municipalities agreed to participate in the project, the principal researcher gathered names and addresses of stroke survivors from the division of public health and environment in each municipality and screened the subjects at their homes, in accordance with the inclusion and exclusion criteria. All stroke survivors were informed about the arrival of the researcher beforehand by municipality officials and made a decision on whether or not to participate in the project.

\section{Inclusion criteria}

Subjects were included if they could follow a 2-3 step command, walked with or without assistive devices, their medical symptoms were stable, had a Brunnstrom's motor recovery level of 3-5 in leg, arm and hand ${ }^{26,36}$, were able to participate in the programme for a period of I hour per week for eight weeks and had given consent to participate in the study.

\section{Exclusion criteria}

Subjects were excluded if they had severe unilateral body neglect, motor apraxia and pain in the affected limb (Visual Analog Scale $\geq 4$ ), and if they were involved in rehabilitation programme from other organisations at the time as this study.

There were 10 participants from Nongkwauy municipality, six from Nongkaew municipality, five from Maerang municipality and six from Makok municipality who met the criteria $(n=27)$. All of these individuals were informed about the research procedure and signed the consent form before commencement of the study.

\section{Instruments}

I. The Ten-Meter Walk Test (or Timed I0-Meter Walk Test) is a commonly used measurement for assessing walking speed. The individual walks without assistance for 10 meters (with or without aids) and the time is taken from the $2^{\text {nd }}$ to the $8^{\text {th }}$ meter point to allow for acceleration and deceleration. The test procedure was as follows:

I.I Start timing when the toes of the leading foot cross the 2-meter mark.

I.2 Stop timing when the toes of the leading foot cross the 8-meter mark.

I.3 Assistive devices can be used, but have to be kept consistent and documented from test to test.

I.4 Individual should perform at the fastest speed possible.

I.5 Collect data from the three trials and calculate the average ${ }^{39}$.

Walkway set-up (Figure I)

I. Measure and mark a 10-meter walkway

2. Add a mark at 2-meters

3. Add a mark at 8 -meters

Figure I: Walkway set up of the Ten-Meter Walk Test

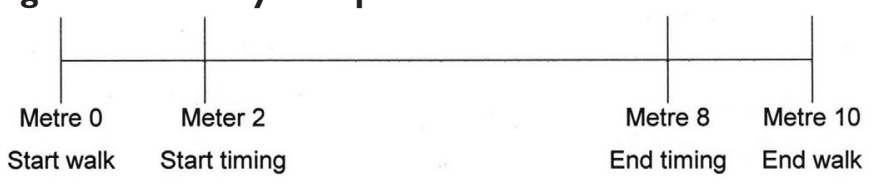

In addition, the walkway surface had to be smooth along the entire 10-meter distance. Research assistants who collected data on walking speed in the present study selected an appropriate walkway either inside or outside the house and the testing walkways used remained the same both at pre-test and post-test for each individual subject.

2. The Fugl-Meyer Assessment ${ }^{25}$ is a well-established stroke motor measurement, iteratively determining active movement at each joint of the paretic extremity. It is recommended for use in stroke rehabilitation trials. Furthermore, it requires few household items to administer and minimal setup. The FMA includes items dealing with the shoulder, elbow, forearm, wrist and hand in the UE and the hip, knee and ankle in the lower extremity (LE). Reflex activity is assessed both in the UE and $\mathrm{LE}$ at the beginning and end of the motor assessment. Balance is examined in sitting and standing positions. Sensation is evaluated by light touch and position senses both in the UE and LE. Range of motion is tested on eight joints, four in each extremity. The FMA consists of I 55 items, with each being rated on a three-point ordinal scale ( 2 points for details performed completely, I point for those performed partially, and 0 for those not performed). The maximum attainable score is 226 . The maximum motor performance score is 66, 34, I4 and 24 points for the UE, LE, balance and sensations, respectively, and 44 points each for passive joint motion and joint pain ${ }^{25}$. This instrument has proved to be highly reliable (overall intra-class correlation coefficient $=0.96$ ), and the intra-class correlation coefficients for subsections of the assessment varied from 0.61 for pain to 0.97 for the $U^{40}$. The researchers in this study 
selected only the UE motor performance test for evaluating the arm and hand function of the participants. The FMA of the UE (FMA-UE) is the most widely used tool in the clinical assessment of post-stroke UE motor function ${ }^{4}$. The measurement properties of the FMA-UE have shown excellent intra-rater reliability $(r=0.995)$, inter-rater reliability $(r=0.992)$, intraclass correlation coefficient (range 0.94-0.99) and internal consistency $(r=0.97)^{42}$. The FMA motor score includes 33 items related to movements of both proximal and distal parts of the UE including reflex testing; ability of movement with and without synergy of shoulder, arm and hand; capacity of hand to hold objects; and hand co-ordination in terms of tremor, dysmetria and speed. The motor domain of the FMA-UE can be administered within 15 minutes. The total score ranges from 0 to 66 . It is best administered to each individual with stroke on a one-to-one basis by a therapist trained in FMA evaluation.

\section{Rehabilitation Education Provided for VHVs}

The selection of VHVs for participation in this study was congruent with the stroke survivors who had been recruited before. VHVs who usually cared for the selected stroke survivors, were invited to participate in the study. There were $10 \mathrm{VHVs}$ from Nongkwauy municipality, six from Nongkaew municipality, five from Maerang municipality and another six from Makok municipality. The research team, consisting of an occupational therapist and a physiotherapist, gave a rehabilitation education presentation to the $\mathrm{VHVs}$ at each of the four municipalities on different days.

The rehabilitation education presentation was conducted for seven hours within one day, from 9 am to $5 \mathrm{pm}$ with a one hour lunch break from $12 \mathrm{pm}$ to I pm. The occupational therapist and physiotherapist provided information for the first three hours as follows:

I. Basic knowledge of stroke, consisting of aetiology, symptoms, recovery stages, therapeutic intervention and complications. This session was conducted by an occupational therapist who was an expert in this field.

2. Gait training in persons with hemiplegia, e.g. gait patterns, gait deviations in stroke survivors, walking training (with and without walking aids), postural balance and basic exercise of muscles in the LE. This session was conducted by a physiotherapist who was an expert in this field.

3. UE function training focused on basic function of the arm and hand, including reaching out for, holding, carrying and releasing objects. The application of bilateral hand activities and weight-bearing tasks for use in activities of daily living were also suggested. The therapist instructed therapeutic exercise and movement techniques that increase and maintain ROM of the UE in persons with stroke, then demonstrated these to VHVs. In addition, advice pertaining to precautions regarding complications during rehabilitation for stroke clients, such as spasticity, contracture, pain, clonus, sensation loss, etc., was given. This session was conducted by an occupational therapist.

Therapists also distributed manuals for stroke rehabilitation to all VHVs. This manual was specifically developed by researchers for general caregivers, including the $\mathrm{VHVs}$, as a user-friendly booklet, containing pictures and explanations with common wording that could be easily understood by people who were not in the medical field.

The last four hours were used for a practice session. Stroke participants, who were under the care of each VHV, were invited to the meeting venue, where the occupational therapist assessed UE function while the physiotherapist evaluated the walking ability of each stroke survivor in front of the VHV. The therapists provided a structured rehabilitation training programme for the VHV who was responsible for that patient, both verbally and in written format which contained concise information and steps of practice. Other $\mathrm{VHVs}$ in the same group attended this session for learning purposes. After that, each VHV trained the stroke participant to walk correctly, to use arm and hand, to exercise both UE and LE and also, where required, practice of standing balance. The practice session of each $\mathrm{VHV}$ took place under the direct supervision of an occupational therapist and physiotherapist. All stroke survivors in the present study received a similar training programme that emphasised walking ability and UE function because the motor recovery of all these participants were at stage $3-5$ on the Brunnstrom scale ${ }^{26}$ which indicated a need for practice both in LE and UE. Both the occupational therapist and physiotherapist had to approve the training skills of VHVs for them be eligible to join the research project. After the training programme, all of the VHVs were approved for participation in the study.

\section{Intervention Programme: Home Visits}

The intervention programme in this study involved visiting the homes of the participants by the trained VHVs, who provided rehabilitation to stroke survivors who met the criteria for treatment at home. They also suggested that caregivers carry out the 8-week programme continuously. The VHVs were required to conduct home visits once a week (I hour per visit), for eight consecutive weeks, with one volunteer visiting one stroke survivor in each case. The researchers contacted each volunteer by phone every two weeks to determine whether there were any obstacles in the execution of the rehabilitation home programme.

\section{Data Collection}

The first research assistant, who was an occupational therapist with at least two years' experience in the field and who was not involved in rehabilitation education, had been trained in data collection (on walking speed and UE function evaluation) and collected data from the homes of the participants within seven days prior to the first home visit by the VHVs.

Data collection at post-test was carried out within seven days after the 8-week programme had ended by a second research assistant who was an occupational therapist with at least two years' experience and who had not been involved with rehabilitation education or data collection at pre-test.

\section{Data Analysis}

I. Descriptive statistics were used for clarifying the sociodemographic data of the participants.

2. The paired t-test was used to compare outcome variables at pre- and post-intervention. The level of statistical significance was set at 0.05 .

\section{RESULTS}

Prior to data analysis, Fisher's Measure of Skewness and Kurtosis $^{43}$ tested normality, which revealed a normal distribution of the studied data. All results were captured in tabular format (see Table II on page 36).

Data from Table III on page 36 show that the participants used significantly less time for walking at post-test than at pre-test $(p<0.05)$. Gait speed at pre-test was 0.17 meters per second $(\mathrm{m} / \mathrm{s})$ and increased to $0.19 \mathrm{~m} / \mathrm{s}$ at post-test. The UE function score was not different between pre-test and post-test.

\section{DISCUSSION}

\section{Walking speed}

Results of this study revealed that walking speed of the participants had increased significantly after the intervention $(=32.18 \pm 9.32)$ when compared to that at pre-test $(=34.73 \pm 8.48)$. This may be because the stroke survivors and their caregivers received knowledge of the correct walking gait, postural balance and due to the LE exercise programme from the trained VHVs, who visited the participants once a week for eight weeks. The stroke survivors were also advised to practise by themselves during each week of the programme. Walking speed can be improved if gait pattern is corrected. Rosa et $\mathrm{al}^{44}$ noted in their study of lower limb co-contraction in stroke subjects during walking that long co- 
Table II: Socio-demographic data of the participants $(n=27)$

\begin{tabular}{|c|c|c|}
\hline $\begin{array}{l}\text { Socio-demographic } \\
\text { data }\end{array}$ & Variables & Number (\%) \\
\hline Gender & $\begin{array}{l}\text { Male } \\
\text { Female }\end{array}$ & $\begin{array}{l}17(62.9) \\
10(37.1)\end{array}$ \\
\hline Age & $\begin{array}{l}31-40 \text { years } \\
41-50 \text { years } \\
51-60 \text { years } \\
>60 \text { years }\end{array}$ & $\begin{array}{c}\text { I (3.7) } \\
\text { I (3.7) } \\
8(29.7) \\
\text { I } 7(62.9)\end{array}$ \\
\hline Marital status & $\begin{array}{l}\text { Single } \\
\text { Married } \\
\text { Divorced } \\
\text { Widowed }\end{array}$ & $\begin{array}{c}6(22.2) \\
18(66.7) \\
1(3.7) \\
2(7.4)\end{array}$ \\
\hline Educational level & $\begin{array}{l}\text { Un-educated } \\
\text { Elementary school } \\
\text { Secondary school }\end{array}$ & $\begin{array}{c}3(1 \mathrm{I} .1) \\
23(85.2) \\
1(3.7)\end{array}$ \\
\hline Affected side & $\begin{array}{l}\text { Left hemiplegia } \\
\text { Right hemiplegia }\end{array}$ & $\begin{array}{l}14(51.8) \\
13(48.2)\end{array}$ \\
\hline Diagnosis & $\begin{array}{l}\text { Haemorrhagic stroke } \\
\text { Thrombotic stroke } \\
\text { Embolic stroke }\end{array}$ & $\begin{array}{c}9(33.3) \\
13(48.2) \\
5(18.5)\end{array}$ \\
\hline $\begin{array}{l}\text { Brunnstrom's stage } \\
\text { of leg recovery }{ }^{26}\end{array}$ & $\begin{array}{l}\text { Stage } 3 \\
\text { Stage } 4 \\
\text { Stage } 5\end{array}$ & $\begin{array}{l}12(44.44) \\
10(37.04) \\
5(18.52)\end{array}$ \\
\hline $\begin{array}{l}\text { Brunnstrom's stage } \\
\text { of arm recovery }{ }^{26}\end{array}$ & $\begin{array}{l}\text { Stage } 3 \\
\text { Stage } 4 \\
\text { Stage } 5\end{array}$ & $\begin{array}{l}\text { I2 (44.44) } \\
\text { II (40.74) } \\
4(14.82)\end{array}$ \\
\hline $\begin{array}{l}\text { Brunnstrom's stage } \\
\text { of hand recovery }\end{array}$ & $\begin{array}{l}\text { Stage } 3 \\
\text { Stage } 4 \\
\text { Stage } 5\end{array}$ & $\begin{array}{l}\text { I5 (55.56) } \\
8(29.63) \\
4(14.81)\end{array}$ \\
\hline $\begin{array}{l}\text { Time length since } \\
\text { onset }\end{array}$ & $\begin{array}{l}<12 \text { months } \\
1-2 \text { years } \\
>2 \text { years }\end{array}$ & $\begin{array}{c}\text { I (3.7) } \\
6(22.2) \\
20(74.4)\end{array}$ \\
\hline Aids used & $\begin{array}{l}\text { None } \\
\text { Single cane } \\
\text { Tripod or Quad cane }\end{array}$ & $\begin{array}{l}3(11.1) \\
7(25.9) \\
17(63.0)\end{array}$ \\
\hline
\end{tabular}

Table III: Comparison of walking speed and UE function of the participants at pre-test and post-test $(n=27)$

\begin{tabular}{|l|c|c|c|c|}
\hline \multirow{2}{*}{ Variables } & \multicolumn{2}{|c|}{ Mean (SD) } & \multirow{2}{*}{$\mathrm{p}$-value } \\
\cline { 2 - 3 } $\begin{array}{l}\text { Walking } \\
\text { speed(seconds) }\end{array}$ & $\begin{array}{c}34.73(8.48) \\
0.17 \text { meters/ } \\
\text { second }\end{array}$ & $\begin{array}{c}32.18(9.32) \\
0.19 \text { meters/ } \\
\text { second }\end{array}$ & 4.18 & $.000 *$ \\
\hline UE function & $36.81(9.59)$ & $37.26(9.67)$ & -0.73 & .474 \\
\hline * $p<0.05$ & & \\
\hline
\end{tabular}

contraction of agonist and antagonist muscles, e.g. quadriceps and hamstrings or gastrocnemius and tibialis anterior, could improve the walking ability and gait patterns of stroke survivors. Physical training relevant to walking, for example, standing balance, the cardio-respiratory system and other gait activities, is a factor that enhances walking speed in persons with hemiplegia resulting from stroke ${ }^{45,46}$. The stroke participants in this study, together with their caregivers, received rehabilitation knowledge, the standing balance programme, exercise techniques and correct gait training from the trained VHVs, which could be a factor of improvement in walking speed. However, gait speed of stroke participants in this study was still very slow (ranged from $0.17 \mathrm{~m} / \mathrm{s}$ to $0.19 \mathrm{~m} / \mathrm{s}$ ) compared to the average speed of stroke survivors by a study of Olney and Richards ${ }^{47}$ that ranged from $0.23 \mathrm{~m} / \mathrm{s}$ to $0.73 \mathrm{~m} / \mathrm{s}$. This may be because the majority of stroke victims who live in rural areas in Thailand did not have an opportunity to receive correct gait training and the exercise programme for LE from the rehabilitation team in hospitals due to the early discharge policy. Some of these people, therefore, practise walking by themselves at home and this resulted in awkward and clumsy movements during locomotion. Spontaneous recovery of motor function would not affect walking ability much in these subjects, since almost all of them had suffered a stroke more than one year prior to the study (Table II). Spontaneous recovery occurs very slowly after a period of one year in stroke survivors ${ }^{48}$.

\section{UE Functions}

Results from this study revealed that the participants' ability scores of UE functions at pre-test $(=36.81 \pm 9.59)$ did not significantly differ from post-test $(=37.26 \pm 9.67)$. This may be because the majority of subjects $(74.10 \%)$ suffered a stroke more than two years prior to the study (Table II), possibly causing a slow recovery rate of muscle function. A number of studies revealed that the recovery of motor function in the affected side of hemiplegic patients is fastest during the first 16 weeks after onset of the condition ${ }^{49}$. ${ }^{50}$ and could continue for up to one year ${ }^{23}$. Better motor function gained at the initial stage of disease can be a predictor of good bodily function at a later stage. In contrast, most persons with stroke who do not recover well at the first stage might not gain good physical function later on.

In addition, the evaluation of the arm and hand demand more function than those in LE e.g. precision grasp, dexterity and coordination ${ }^{51}$. This means that the training of UE function is more complex than those in the LE. It can be one of the causes of lower progress scores in UE assessment than those in the LE even in participants with similar impairments. The epidemiological data of motor recovery after stroke reported by Kwakkel, Kollen \& Wagenaar ${ }^{52}$ revealed that most stroke survivors (70\% to $80 \%$ ) regained the ability to walk, whereas only between 30 and $66 \%$ of stroke survivors were able to use their affected arm due to a variety of complications. This implies that the training of hand function in stroke survivors needs more expertise than that of the VHVs in the present study.

Although the scores obtained for UE functions did not improve from pre- to post-test in the participants of this study, their participation could be beneficial for preventing complications, e.g. muscle contracture, joint stiffness, etc., as these people learn and practise the techniques such as active and passive ROM, basic muscle exercise, from the trained $\mathrm{VHVs}$.

\section{Limitations}

The time of seven hours provided for rehabilitation education was quite short for the VHVs. However, the research team solved the problem by providing only fundamental theories and structured practice that could be applied easily. The practice programme for VHV's aimed at home-based rehabilitation, was presented verbally as well as in a step-by-step, written format by therapist with expertise in the field. Furthermore, therapists also distributed a manual to all VHVs on basic home rehabilitation for hemiplegic patients in order to offer more detailed instruction. In addition, research teams made phone calls to VHVs once every two weeks in order to ascertain whether there were any obstacles or problems during the home visits and if so, assisted in overcoming them and in achieving the rehabilitation objectives. Another limitation was the absence of a control group for comparison of the outcome variables. Researchers, therefore, set the inclusion criteria to recruit as much homogeneity among the subjects as possible, and also used different research assistants for collecting data between pre-test and post-test to strengthen the reliability of the results. However, it is recommended that a control group be included in future studies.

\section{CONCLUSION}

Rehabilitation education and training of VHVs who participate in home visits to stroke survivors is beneficial in improving walking 
ability and maintaining UE function, especially of those patients living in the remote rural areas of Thailand. This strategy lessens the cost and time burdens associated with home visits for healthcare providers who are based in hospitals or rehabilitation institutions ${ }^{53}$. The results of this study demonstrate that trained VHVs can be part of the rehabilitation team that improves the functional performance of disabled people in the community, particularly in developing countries.

\section{ACKNOWLEDGEMENTS}

The authors would like to thank the committee members of the academic service programme, Faculty of Associated Medical Sciences, Chiang Mai University, Thailand, for their support and grants that made this project possible. And many thanks to the VHVs and stroke survivors who willingly participated in the study.

\section{REFERENCES}

I. Khemthong S, Posawang P, Timayorm P. Effectiveness of health system program with occupational therapy on quality of life and self-efficacy after stroke. The Journal of Occupational Therapist Association of Thailand. 2009; 14: 26-34.

2. Sitanon N, Chaweangchoa B. Knowledge and understanding of caregivers in hemiplegic's complication prevention. The Journal of Occupational Therapist Association of Thailand. 2004; 9: I- 10.

3. Forster A, Young J. Incidence and consequences of fall due to stroke: a systematic inquiry. Br Med J. 1995; 31 I: 83-6.

4. Nascimento LR, de Oliveira CQ, Ada L, Michaelsen SM, TeixeiraSalmela LF. Walking training with cueing of cadence improves walking speed and stride length after stroke more than walking training alone: a systematic review. Journal of Physiotherapy. 20I5; 6I(I): 10-5.

5. Said CM, Goldie PA, Culham E, Sparrow WA, Patla AE, Morris ME. Control of lead and trail limbs during obstacle crossing following stroke. Phys Ther. 2005; 85: 4I3-27.

6. Anderson HE, Eriksen K, Brown A, Schultz-Larsen K, Forchhammer $\mathrm{BH}$. Follow-up services for stroke survivors after hospital dischargea randomized control study. Clin Rehabil. 2002; 16: 593-603.

7. Yavuzer G, Selles R, Sezer N, Sütbeyaz S, Bussmann JB, Köseoğlu $F$, et al. Mirror therapy improves hand function in subacute stroke: A randomized controlled trial. Arch Phys Med Rehabil. 2008; 89: 393-8.

8. Bunyamark T. Occupational therapy in stroke. In: Chinchai P, Bunyamark T, editors. Occupational Therapy for Persons with Neurological Conditions. Chiang Mai: Faculty of Associated Medical Sciences, Chiang Mai University; 2005: 202-40.

9. Gillen G. Cerebrovascular accident/Stroke. In: Pendleton HM, Schultz-Krohn W, editors. Occupational Therapy: Practice Skills for Physical Dysfunction 6th ed. St. Louis, MS: Mosby, Inc; 2006: 802-37.

10. Stein J, Brandstater ME. Stroke rehabilitation. In: Frontera WR, DeLisa JA, Gans BM, Walsh NE, Robinson LR, Basford JR, editors. DeLisa's Physical Medicine \& Rehabilitation: Principles and practice. 5th ed. Philadelphia, PA: Lippincott Williams \& Wilkins; 20I0: 55I74.

II. Alzahrani M, Dean CM, Ada L. Relationship between walking performance and types of community-based activities in people with stroke: an observational study. Brazil Journal of Physical Therapy. 2010; 15: 45-5I.

12. Mthembu TG, Brown Z, Cupido A, Razack G, Wassung D. Family caregivers' perceptions and experiences regarding caring for older adults with chronic diseases. South African Journal of Occupational Therapy. 2016; 46: 83-8.

13. Kowitt SD, Emmerling D, Fisher EB, Tanasukarn C. Community health workers as agents of health promotion: Analyzing Thailand's village health volunteer program. J Community Health. 20I5; 40: 780-8.

14. Sukkumnerd S, Ajjimangkul S, Ajjimangkul S-R, Kongsuwiwat K. Trends of demographic data of public health volunteers in the future. In: Chuengsatiansup K, Sukkumnerd S, Ajjimangkul S, Ajjimangkul S-R, Kongsuwiwat K, Sooksut P, et al., editors. Public Health Volunteers: Volunteer spirit and Thai's well-being. 2 ed. Nonthaburi: Meedee Graphic Co. Limited; 2008: 31-78.

15. Obembe AO, Olaogun MO, Adedoyin R. Gait and balance per- formance of stroke survivors in south-western Nigeria- A crosssectional study. Pan Afr Med J. 20 I4; I7(Supp I): 6: I-6.

16. Nijenhuis S, Prange G, Amirabdollahian F, Sale P, Infarinato F, Nasi $\mathrm{N}$, et al. Feasibility study into self-administered training at home using an arm and hand device with motivational gaming environment in chronic stroke. Journal of Neuroengineering and Rehabilitation (JNER). 2015; 12:89.

17. Kosak MC, Reding MJ. Comparison of partial body weight-supported treadmill gait training versus aggressive bracing assisted walking post stroke. Neurorehabilitation and Neural Repair. 2000; 14: I3-9.

18. Jorgenson $\mathrm{H}, \mathrm{Nakayama} \mathrm{H}$, Raaschou H, Olsen T. Recovery of walking function in stroke patients: The Copenhagen Stroke Study. Arch Phys Med Rehabil. 1995; 76: 27-32.

19. Bohannon RW, Horton MG, Wikholm JB. Importance of four variables of walking to patients with stroke. Int J Rehabil Res. 1991; 14(3): 246-50.

20. Bassile CC, Hayes SM. Gait awareness. In: Gillen G, editor. Stroke Rehabilitation: A function-based approach. 3 rd ed. St. Louis, Missouri: Elsevier Mosby; 20II: 389-416.

2I. Gillen G. Cerebrovascular accident/stroke. In: Pendleton HM, Schultz-Krohn W, editors. Pedretti's Occupational Therapy: Practice Skills for Physical Dysfunction. 7th ed. St. Louis, Missouri: Elsevier Mosby; 2013: 844-80.

22. Feenstra W, Tepper M, Boonstra AM, Otten B, de Vries S. Recovery of motor imagery ability in the first year after stroke. Int J Rehabil Res. 2016; 39(2): I7I-5.

23. Muellbacher W, Richards C, Ziemann U, Wiltenberg G, Weltz D, Boroojerdi B, et al. Improving hand function in chronic stroke. Arch Neurol. 2002; 59: 1278-82.

24. Gillen G. Upper extremity function and management. In: Gillen G, editor. Stroke Rehabilitation: A function-based approach. 3rd ed. St. Louis, Missouri: Elsevier Mosby; 201 I: 218-79.

25. Gladstone DJ, Danells CJ, Black SE. The fugl-meyer assessment of motor recovery after stroke: a critical review of its measurement properties. Neurorehabilitation and Neural Repair. 2002; 16: 232-40.

26. Schultz-Krohn W, Royeen CB, Mccormack G, Pope-Davis SA, Jourdan JM. Traditional sensorimotor approaches to intervention. In: Pendleton HM, Schultz-Krohn W, editors. Occupational Therapy: Practice Skills for Physical Dysfunction. 6th ed. St. Louis, MS: Mosby, Inc; 2006: 726-68.

27. Dobkin $\mathrm{BH}$. Rehabilitation after stroke. The New England Journal of Medicine. 2005; 352: 1677-184.

28. Fasoli SE, Krebs HI, Stein J, Frontera WR, Hughes R, Hogan N. Robotic therapy for chronic motor impairment after stroke: follow-up results. Arch Phys Med Rehabil. 2004; 85: I I06-I I.

29. Hung GKN, Li CTL, Yiu AM, Fong KNK. Systematic review: Effectiveness of mirror therapy for lower extremity post-stroke. Hong Kong Journal of Occupational Therapy. 2015; 26: 5I-9.

30. Dobkin BH. Strategies for stroke rehabilitation. Lancet Neurol. 2004; 3: 528-36.

31. Bhutta ZA, Lassi ZS, Pariyo G, Huicho L. Global experience of community health workers for delivery of health related millennium development goals: A systematic review, country case studies, and recommendations for integration into national health systems. Global Health Workforce Alliance. 2010; I: 249-6I.

32. Kauffman KS, Myers DH. The changing role of village health volunteers in northeast Thailand: An ethnographic field study. Int J Nurs Stud. 1997; 34 (4): 249-55.

33. Dans A, Ng N, Varghese C, Tai E, Firestone R, Bonita R. The rise of chronic non-communicable diseases in southeast Asia: Time for action. The Lancet. 20I I; 377(9766): 680-9.

34. Thorsén A-M, Holmqvist LW, de Pedro-Questa J, von Koch L. A randomized controlled trial of early supported discharge and continued rehabilitation at home after stroke: Five-year follow-up of patient outcome. Stroke. 2005; 36: 297-302.

35. Chinchai P, Bunyamark T. Effects of caregiver education in health promotion and stroke rehabilitation on the community participation of stroke survivors. The Journal of Occupational Therapist Association of Thailand. 2008; 13: 1-9.

36. Chinchai P. The Brunnstrom Movement Therapy Approach. In: Chinchai P, editor. Occupational Therapy for Persons with Neurological Conditions. 4th ed. Chiang Mai: Siampimnana, Co. Ltd.; 20। 7: 77-86. 
37. Scivoletto G, Tamburella F, Laurenza L, Foti C, Ditunno JF, Molinari M. Validity and reliability of the 10-m walk test and the 6-min walk test in spinal cord injury patients. Spinal Cord. 20I I; 49: 736-40.

38. Rehab Measures: 10 Meter Walk Test [Internet]. 2010 [cited I5th, June, 20I5]. Available from: http://www.rehabmeasures.org/Lists/ RehabMeasures/DispForm.aspx?ID $=90$ I.

39. Sungkarat S. Rehabilitation of Patients with Brain Lesion: Theory to practice. Chiang Mai: Siam Nana Printing; 2013.

40. Sanford J, Moreland J, Swanson LR, Stratford PW, Gowland C. Reliability of the Fugl-Meyer assessment for testing motor performance in patients following stroke. Phys Ther. 1993; 73(7): 447-54.

4I. van Wijck F, Pandyan A, Johnson F, Barnes M. Assessing motor deficits in neurological rehabilitation: Patterns of instrument usage. Neurorehabilitation and Neural Repair. 20II; 15: 23-30.

42. Woodbury M, Velozo C, Richards L, Duncan P, Studenski S, Lai S. Dimensionality and construct validity of the Fugl-Meyer Assessment of the Upper Extremity. Arch Phys Med Rehabil. 2007; 88: 7I 5-23.

43. Munro BH. Statistical Methods for Health Care Research. Philadelphia, PA: Lippincott Williams \& Wilkins; $200 \mathrm{I}$.

44. Rosa MC, Marques A, Demain S, Metcalf CD. Lower limb cocontraction during walking in subjects with stroke: A systematic review. J Electromyogr Kinesiol. 20 I4; 24: I-I0.

45. Olaleye OA, Hamzat TK, Owolabi MO. Stroke rehabilitation: Should physiotherapy intervention be provided at a primary health care centre or the patients' place of domicile?. Disabil Rehabil. 2014; 36(I): 49-54.

46. Saunders DH, Sanderson M, Brazzelli M, Greig CA, Mead GE. Physical fitness training for stroke patients. 2013 November, 24th, 2014 10:CD003316.

47. Olney SJ, Richards C. Hemiparetic gait following stroke. part I: characteristics. Gait Posture. 1996; 4(2): 149-62.

48. Andrews K, Brocklehurst JC, Richards B, Laycock PJ. The rate of recovery from stroke and its measurement. Int Rehabil Med. 198I; 3: |55-6|.

49. Broeks JG, Lankhorst GJ, Rumping K, Prevo AJ. The long-term outcome of arm function after stroke: results of a follow-up study. Disabil Rehabil. 1999; 21 (8): 357-64.

50. Jorgensen HS, Nakayama H, Raaschon HO, Vive-Larson J, Stoier M, Olsen TS. Outcome and time course of recovery in stroke. Part II: time course of recovery. The Copenhagen stroke study. Arch Phys Med Rehabil. 1995; 76: 406-I2.

5I. Paci M, Nannetti L, Casavola D, Lombardi B. Differences in motor recovery between upper and lower limbs: does stroke subtype make the difference? Int J Rehabil Res. 2016; 39(2): 185-7.

52. Kwakkel G, Kollen B, Wagenaar R. Therapy impact on functional recovery in stroke rehabilitation: a critical review of the literature. Physiother Can. 1999; 85: 377-91.

53. Sim S, Barr CJ, George S. Comparison of equipment prescriptions in the toilet/bathroom by occupational therapists using home visits and digital photos, for patients in rehabilitation. Australian Occupational Therapy Journal. 2015; 62: 132-40.

\section{Corresponding Author}

\section{Pisak Chinchai}

pisak.c@cmu.ac.th 